\title{
11. Linear Plasmid DNA in Pyrenophora graminea, a Fungal Pathogen of Barley
}

\author{
By Kazuyuki Hiratsuka, Shigetou Namba, Shuichi Yamashita, \\ and Tsuneo Tsuchizaki \\ Faculty of Agriculture, The University of Tokyo, \\ Bunkyo-ku, Tokyo, 113
}

(Communicated by Naohide HiratsukA, M. J. A., March 13, 1989)

Introduction. Most extrachromosomal elements of fungi are double-stranded RNAs (dsRNAs). In almost all cases the dsRNA is viral in origin (Buck 1986). However, in recent years linear plasmid DNAs have been identified in several plant pathogenic fungi. They can be used to identify specific fungal strains (Kistler and Leong 1986) and may be related to pathogenicity (Hashiba et al. 1984).

The filamentous fungus Pyrenophora graminea Ito et Kuribayashi apud Ito is a causal agent of important disease of barley. In addition to the dsRNA viruses (Hiratsuka et al. 1985), we report here the presence of linear plasmid DNA of this fungus.

Materials and methods. Strains. Fungal strains used in this study were isolated in 1984 and 1985 from barley leaves. Its identification as $P$. graminea was confirmed by mitochondrial DNA restriction endonuclease digestion patterns (Hiratsuka et al. unpublished data). Stock cultures of all isolates were maintained on slants of potato dextrose agar supplemented with $0.3 \%$ yeast extract.

Preparation of nucleic acid. For preparing mitochondrial fraction, fungal isolates were grown in stationary cultures on potato dextrose broth containing $0.3 \%$ yeast extract at $20^{\circ} \mathrm{C}$. Mycelium was harvested from 10- to 15-day-old cultures by centrifugation at $9,000 \mathrm{rpm}$ for $10 \mathrm{~min}$ (Hitachi RPR20 rotor), and washed twice in $0.5 \mathrm{M}$ mannitol, $50 \mathrm{mM}$ Tris, $1 \mathrm{mM}$ EDTA, $0.2 \%$ bovine serum albumin and 1\% 2-mercaptoethanol, $\mathrm{pH} 7.8$ (MTE). The mycelium (typically a volume of $10-15 \mathrm{ml}$ of packed cells) was resuspended in $60 \mathrm{ml}$ of MTE medium and homogenized using a glasshomogenizer. The homogenate was centrifuged twice at $3,000 \mathrm{rpm}$ for $10 \mathrm{~min}$ (Hitachi RPR20 rotor), and the resulting supernatant was recentrifuged at $10,000 \mathrm{rpm}$ for $20 \mathrm{~min}$ at $4^{\circ} \mathrm{C}$ to pellet mitochondria. To digest nuclear DNA, the pelleted materials were resuspended in MTE containing $10 \mathrm{mM} \mathrm{MgCl}{ }_{2}$ and treated with DNase I $(50 \mu \mathrm{g} / \mathrm{ml})$ for $30 \mathrm{~min}$ at $37^{\circ} \mathrm{C}$. The mitochondrial fraction was washed twice with $50 \mathrm{mM}$ Tris- $\mathrm{HCl}$ buffer containing $0.5 \mathrm{M}$ sucrose and $20 \mathrm{mM}$ EDTA. The final pelleted materials were lysed in $50 \mathrm{mM}$ Tris- $\mathrm{HCl}$ buffer $(\mathrm{pH} 8.0)$ containing $20 \mathrm{mM}$ EDTA, $5 \%$ sodium lauroyl sarcosine and proteinase $\mathrm{K}(300 \mu \mathrm{g} / \mathrm{ml})$. Then the suspension was incubated for $1 \mathrm{hr}$ at $60^{\circ} \mathrm{C}$ followed by phenol-chloroform extraction. The upper aqueous phase was precipitated by the addition of one volume of isopropanol. Extraction of total cellular nucleic acid from mycelium was performed as described previously (Hiratsuka et al. 1987).

Gel electrophoresis. Analytical electrophoresis of DNA was in horizontal 0.8\%-1.2\% agarose submarine gels. Preparative electrophoresis was in $1.0 \%$ agarose gels, followed by electroelution of the desired bands (Maniatis et al. 1982).

Electron microscopy. Purified plasmid DNA was prepared for electron 
microscopy by the protein film droplet method (Lang and Mitani 1970). The preparations were observed by dark-field electron microscopy in a Hitachi H-800 electron microscope with a tilt beam system. Open circular pUC19 DNA was used as a molecular standard.

Results. Detection of plasmid DNA by gel electrophoresis. Mitochondrial and total cellular DNAs were isolated from a number of wild strains of $P$. graminea. Agarose gel electrophoresis indicated the presence of extrachromosomal bands in several isolates but most of them were double-stranded RNA which were confirmed by RNase A treatment. Out of thirteen isolates of $P$. graminea, only two strains (PG425B and PG426N) were found to contain plasmid DNA components of $11 \mathrm{~kb}$ with respect to lambda phage DNA restriction endonuclease digested linear markers (Fig. 1). We focused our attention on the $11 \mathrm{~kb}$ element from strain PG425B, designated pPG42.

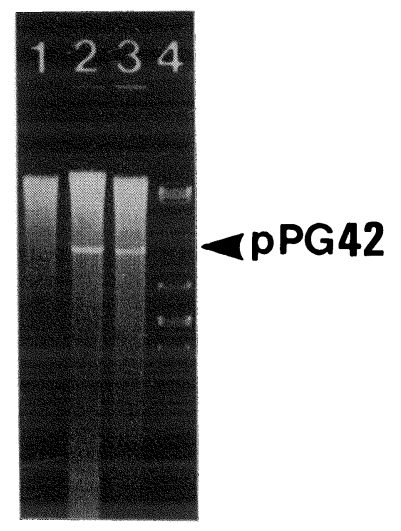

Fig. 1

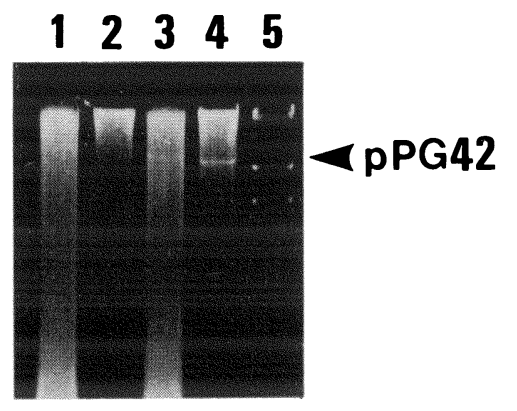

Fig. 2

Fig. 1. Electrophoresis in a $0.8 \%$ agarose gel of DNA preparations of mitochondrial fraction from isolates of Pyrenophora graminea, using Tris-acetate buffer. (1) Strain PG517TA; (2) strain PG425B; (3) strain PG426N; (4) lambda phage DNA digested with EcoRI.

Fig. 2. Electrophoresis in a 1.0\% agarose gel of DNA preparations of total cellular and mitochondrial fraction, using Tris-acetate buffer. (1) Total cellular DNA of strain PG619C; (2) mitochondrial fraction DNA of strain PG619C; (3) total cellular DNA of strain PG425B; (4) mitochondrial fraction DNA of strain PG425B; (5) lambda phage DNA digested with HindIII.

Cellular localization of $p P G 42$. The plasmid band was detected not only in total cellular nucleic acid sample, but also in the DNase treated mitochondrial fraction. Fig. 2 indicates that pPG42 was localized within the mitochondrion, but our experiment did not exclude the possibility that the plasmid components also existed within the cytoplasm or nucleus.

Electron microscopy. Samples containing pPG42 were examined by electron microscopy. The pPG42 molecules were linear with defined ends (Fig. 3). The mean contour length of linear molecules was in good agreement with the expected value calibrated by gel electrophoresis.

Discussion. Linear plamids were detected in eukaryotes including higher plants, yeast and several filamentous fungi (Esser et al. 1983). Analysis of the DNA from $P$. graminea has revealed the presence of a linear DNA plasmid of 


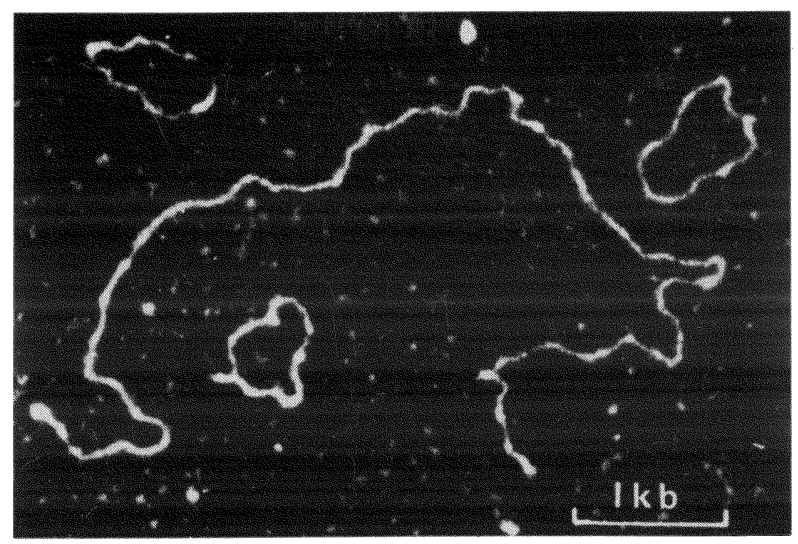

Fig. 3. Electron micrograph of pPG42 and pUC19 DNA (circular molecules). The bar represents $1 \mathrm{~kb}$.

$11 \mathrm{~kb}$ (pPG42) which appears to be mitochondrial in origin. Among plant pathogenic fungi, linear plasmids have been reported in Claviceps purpurea (Tudzynski et al. 1983), Ceratocystis fimbriata (Giasson and Lalonde 1987; Normand et al. 1987) and Tilletia controversa (Kim et al. 1988). These plasmids and pPG42 have common features such as linearity, size and localization. The role of plasmids are not necessarily clear, but it is of considerable interest that the structural features of these elements suggest the similarity to a kind of transposable element. Further structural analysis of pPG42 is now under way.

The DNA isolation procedure described in this study is simple and efficient, and has been found to be equally suitable for several filamentous fungi (Hiratsuka et al. unpublished data). We are now extending our research to other plant pathogenic fungi.

\section{References}

Buck, K. W. (1986) : Fungal Virology (ed. Buck, K. W.). CRC press, Boca Raton, Florida, pp. 1-84.

Esser, K. et al. (1983) : Curr. Genet., 7, 239-243.

Giasson, L., and Lalonde, M. (1987): ibid., 11, 331-334.

Hashiba, T. et al. (1984): J. Gen. Microbiol., 130, 2067-2070.

Hiratsuka, K. et al. (1985) : Ann. Phytopath. Soc. Japan, 51, 57-58 (abstr.).

(1987): ibid., 53, 638-642.

Kim, K. W. et al. (1988) : Can. J. Bot., 66, 1098-1100.

Kistler, H. C., and Leong, S. A. (1986): J. Bacteriol., 167, 587-593.

Lang, D., and Mitani, M. (1970): Biopolymers, 9, 373-379.

Maniatis, T. et al. (1982) : Molecular Cloning. Cold Spring Harbor.

Normand, P. et al. (1987) : Curr. Genet., 11, 335-338.

Tudzynski, P. et al. (1983): ibid., 7, 145-150. 